\title{
Should Patent Protection Be
}

\section{Extended to All Developing}

\section{Countries?}

\author{
Alan V. Deardorff
}

\section{INTRODUCTION}

\begin{abstract}
$\widetilde{\mathfrak{U}}$ HE Uruguay Round has extended the scope of GATT multilateral trade negotiations well beyond the tariffs that had occupied most previous negotiations. 'In addition to various non tariff barriers (which had also been dealt with to a degree in the Tokyo Round, as discussed in Deardorff and Stern 1983 and 1986), the Uruguay Round dealt with issues of trade in services, international investment, and intellectual property. Since these 'new issues' have conceptually quite different characteristics than the tariffs of previous negotiations, it is appropriate to examine them afresh to determine whether the objectives of the Uruguay Round negotiations can be considered economically sound. This paper describes such an analysis for a particular aspect of the intellectual property negotiations - patent rights - and in the process voices some skepticism about this aspect of the Uruguay Round's objectives.

Inclusion of 'Trade Related Intellectual Property' issues, or TRIPs, in the Uruguay Round agenda was done largely at the insistence of the United States. Firms in the United States have long been concerned that their position at the cutting edge of technological progress was being eroded by unauthorised copying of their intellectual property elsewhere in the world. While export of such 'copied' products back into the United States might be restricted under US law, this would provide little help in competition with the 'pirate' firms in third-country markets.
\end{abstract}

ALAN V. DEARDORFF is Professor of Economics and Public Policy in the Department of Economics and Institute of Public Policy Studies at the University of Michigan, Ann Arbor, Michigan, USA.

'This paper reflects and draws upon the analysis in Deardorff (1990), which was originally written under the title, 'Should Patent Protection Be Extended to All Countries?' I have benefited from the comments of the many individuals cited there, whose names I will not repeat. The present paper has also benefited especially from the comments and suggestions of Robert M. Stern and John Whalley. 
And it would provide no help at all in the countries of the copying firms themselves, since these countries typically have not honoured or enforced US concepts of intellectual property rights. Therefore there has been a sizable US constituency in favour of extending US ideas of intellectual property to the rest of the world. The negotiations under the Uruguay Round were intended, at least by the United States, to achieve this objective.

\section{SHOULD THE GATT BE INVOLVED?}

Early in the debate, there was some question as to whether the GATT was an appropriate place to raise issues of international intellectual property. These issues have, since 1970, been under the jurisdiction of the World Intellectual Property Organization (WIPO), and many developing countries especially argued that WIPO should remain their sole arbiter. They feared that under GATT their powers would be diminished relative to the industrialised countries, which of course was exactly the reason that the United States and other industrialised countries wanted to move the issue into GATT. More to the point, it was argued that intellectual property issues are not directly issues of trade or of trade barriers, and hence they are not appropriate to the underlying mission of the GATT. It was for this reason that the Uruguay Round negotiating group was charged to deal, not with intellectual property issues generally, but only with 'trade related' ones, hence TRIPs. In practice, of course, in an interdependent world economy just about anything is trade related in some way, and the negotiations have dealt with intellectual property protection quite generally.

As its name suggests, intellectual property 'protection' is a surprising issue for the GATT to be dealing with in another way. That is, on issues of commercial policy, the GATT's mission has always been to prevent, or at least to circumscribe, countries' efforts to 'protect' their domestic industries. Now, in the TRIPs area, the GATT is being called upon to extend protection, not restrict it. Of course the concepts of protection are different in the two cases. Proponents of the TRIPs negotiations would argue that protection of intellectual property is needed to permit the owners of that property to export the products that embody their innovations. Therefore intellectual property protection, despite its name, is said to be pro-trade.

On the other hand, one could also take the view that the GATT's mission has been to promote the free international flow of goods in trade, and that if that mission is indeed extended to intellectual property, it should also promote the free international flow of ideas. From that perspective, again, the goal of the Uruguay Round negotiations in restricting this free flow may be viewed as perverse.

I should note that proponents of intellectual property protection also argue that such protection actually enhances the international dissemination of ideas. By granting and enforcing patent rights internationally, for example, owners of the 
patents will no longer be forced to keep the details of their inventions secret, and indeed they will be forced to make them public as part of their patent applications. Thus the knowledge itself will indeed be disseminated more freely, not less, and it is only the use of this knowledge that will be restricted. For the purpose of this paper, I will assume that access to knowledge without the ability to use it provides no economic benefit, although I acknowledge that this is not always the case. ${ }^{2}$

\section{ARE THESE REALLY RIGHTS?}

Before turning to a discussion of the costs and benefits of intellectual property protection, I should first ask whether intellectual property rights are really 'rights', in the same sense as the basic human rights that modern societies now appropriately defend. If intellectual property rights are human rights in this sense, then the costs and benefits of protecting them are less of an issue. One might still ask whether it makes sense to broaden the scope of the GATT to defend human rights, but one could agree that some international agency should be charged with the task.

Proponents of intellectual property protection in the industrialised countries often speak of them in these terms. Just as one is entitled to the fruits of one's labour - and we therefore outlaw slavery - one is also entitled to the fruits of one's creative activity. Violators of intellectual property rights are spoken of in pejorative terms, as pirates, counterfeiters, and thieves. Lobbyists for intellectual property protection report the economic 'losses' due to the absence of this protection, measured as the sales that, say, patent owners could have made in countries without patent protection, without even raising the question of whether they were in any sense entitled to these sales. ${ }^{3}$

Yet there are several reasons to be skeptical that intellectual property rights should enjoy the same status as basic human rights, or even as other property rights.

First, as is the case with certain other property rights, our conception of intellectual property rights is largely cuiture specific. In the traditional Chinese culture, for example, there is nothing onerous about copying another's artistic creation. On the contrary, copying an artist is the highest compliment one can pay him. As I understand it, this attitude also carries over to other forms of intellectual property, such as the written word. I do not know, unfortunately, the traditional Chinese attitude towards patent rights.

\footnotetext{
2 For example, if one is engaged in innovation, then knowledge of the details of other innovations can be quite helpful as a guide to new ones. Since I will be discussing extension of patent protection to countries where, by assumption, inventive activity is not being undertaken, this consideration will not arise

'These 'losses' are often also exaggerated. That is, it may be assumed that all illegal sales replace legal sales, unit for unit. even though legal sales would presumably be at a higher price and hence a lower quantity. And the total value of lost sales is typically taken as an economic loss, without deducting costs.
} 
Second, even in Western culture, rights to intellectual property extend only to particular forms of creative activity, and as new forms appear they are not automatically covered, but are subject to negotiation. In US law, for example, ideas cannot be copyrighted. It is only the expression of ideas, in written or other form, that is protected by copyright, and it is only the embodiment of ideas in physical products or processes that is protected by patents. Implicitly our culture recognises that not all creations are the property of their creator. Instead we appear to have determined which creations to protect, and which not, on more practical grounds.

Similarly, even for those categories of intellectual property that our culture and our laws do choose to protect, we do not provide that protection in an unlimited way. This is most obvious in the case of patents, which are granted for only a limited number of years. Even this number, which is 17 in the United States, differs from country to country, again presumably on practical grounds. There is surely nothing in philosophy that would grant an inventor an inalienable right to his invention for exactly 17 years, and then remove that right completely thereafter. Instead, implicitly again, we seem to recognise that there are both costs and benefits associated with patent protection, and that balancing these costs and benefits requires that we extend patent protection for a while, but not indefinitely.

I will argue that the same sort of tradeoff of costs and benefits may apply geographically, as well as over time. There are indeed benefits from a certain amount of patent protection that outweigh their costs, and these benefits suggest that we grant an inventor an exclusive market for his product. But this exclusive market need not be unlimited, either in time or in space, in order to generate some return on the invention. Whether the extent of this market should be limited, or not, ought to depend on a weighing of the costs and benefits to the world as a whole, and this calls for the sort of analysis that is described below.

In any case, it seems clear that our society has already accepted the argument that costs and benefits matter, and that unlimited intellectual property protection is not an inalienable right. It remains to be seen what these costs and benefits are and how they may best be balanced.

Costs and benefits matter in two ways. First, taking the perspective of the world as a whole, if the costs of extending intellectual property protection exceed the benefits, then extending it is inefficient and should be rejected from a world welfare point of view. Second, when the incidence of these costs and benefits is not uniform, with the costs instead being borne disproportionately by one group in society and the benefits largely accruing to another, then the distributional implications of extending intellectual property protection should also be considered. I will argue first that, taking the world point of view, extension of intellectual property protection to the entire world is inefficient. Therefore, if such protection is extended beyond the countries that currently provide it, the process should stop short of covering the entire world. In addition, taking distributional considerations into account, I will also argue that the appropriate countries to be left out of a 
system of otherwise global intellectual property protection should be the poorest of developing countries.

I shall restrict attention in the remainder of the paper to patent protection, leaving aside the other two major categories of intellectual property protection: copyrights and trade marks. I do this in part for simplicity of exposition. But I also do it in recognition that the case for these other two forms of protection as fundamental rights may rest on firmer foundations. Abuse of trademarks, for example, may be condemned as simply being deceptive, and therefore trademarks might be defended by law along with other forms of truth in packaging. ${ }^{4}$ And in a different sense, we seem to recognise a writer's inherent claim to the product of his work on a more unlimited basis than a patent, when we grant copyrights that are renewable for the lifetime of the author.

\section{COSTS AND BENEFITS OF EXTENDING PATENT PROTECTION}

If there were no patent rights at all or any other means for an inventor to secure a return to invention, such as trade secrets or a government subsidy to research, there would presumably be nothing invented. ${ }^{5}$ Inventors and the public both would lose. The inventor would lose the profit that could have been collected from selling the invention to the public. The public would lose the consumer surplus from consuming ${ }^{6}$ or otherwise using the invention. ${ }^{7}$ Thus, in a sense there are no costs, and only benefits, to introducing a system of patent protection.

However, once a limited system of patent protection is in place, providing inventors exclusive rights to sell their inventions to a certain market that is limited either in time or in space, then there are indeed both costs and benefits to extending that protection to a larger market. Both arise from the fact that patent rights grant the patent holder the right to charge a monopoly price, or to collect the rents from charging such a price by licensing someone else to do so. On the one hand, the

\footnotetext{
${ }^{4}$ Or perhaps, this is not so much a matter of fundamental right as just a case where benefits so clearly outweigh costs.

"I ignore the very real possibilities that inventors do it just for the fun, for the glory, or for the altruistic motive of benefiting civilisation. Many inventions undoubtedly have appeared for these reasons, though even these, at the margin, might have been further stimulated by an economic incentive. Given my purpose of arguing for limitation of patent protection, such motives would only strengthen my case.

${ }^{h}$ For simplicity of exposition, I will usually assume that the invention is a final good. Inventions of intermediate inputs and process innovations can be handled similarly, though it is then necessary to work through the markets of the goods they help to produce to get to the consumer surplus, and there is the additional possibility of imperfectly competitive downstream producers capturing part of the surplus. See Chin and Grossman (1990) for an analysis of process innovation that reaches some of the same conclusions that I describe here.

${ }^{7}$ Loss to consumers assumes, of course, that the inventor would not have succeeded in pricing as a perfectly discriminating monopolist, and hence in extracting all of the potential consumer surplus.
} 
monopoly profits add to the incentive to invent, and this will in general lead to a larger amount of invention taking place. This is a benefit, so long as the level of invention is already suboptimal, which in general it will be. On the other hand, the monopoly price distorts consumer choice, and this leads to a suboptimal quantity of invented goods being consumed. This is a cost, so long as some positive amount of invention would have taken place without extending the market.

To elaborate a bit, suppose first that there is only a single market, and that patent rights are granted for all of it. The monopoly profits from serving that market will induce a certain amount of invention. This will be whatever level of invention will balance the expected returns, in the form of monopoly profits, against the expected costs of invention. This situation will be much better than no invention at all, but it will be less than optimal in two ways. On the one hand, because consumers of the invented goods pay monopoly prices instead of perfectly competitive prices which would be lower, they will consume too little of the goods that are invented and will therefore enjoy less consumer surplus than would have been possible. At the same time, because consumers do derive some consumer surplus even with monopoly pricing, the inventing monopolists fail to earn monopoly profits equal to the entire benefit to society that is generated by their inventions. This may sound only fair, but it means that their incentive to invent is not as great at the margin as it should be from society's point of view, and therefore that the level of invention will also be suboptimal. That is, in a world where a great many potential inventions are possible, there will be some inventions that could have benefited consumers more than they cost to invent, but that inventors will not have found it profitable to pursue.

These two aspects of suboptimality give rise to both the benefit and the cost of extending patent protection to a larger, or an additional, market. Suppose there is an additional, call it foreign, market that has not previously granted patent protection. If the monopolist-inventors had previously also been able to deny potential producers in that market access to their technology, in part by refusing to sell their products to the market's consumers, then extending patent protection will create only benefits, through three different channels. First, foreign consumers gain access to the new products, which they did not have at all before. Second, monopolist inventors in the home market gain additional monopoly profits on foreign sales of the goods they would have invented anyway. Third, these additional profits expand the return on invention and cause more invention to be undertaken. These additional inventions generate still more monopoly profit for inventors, plus additional consumer surplus for consumers in both markets.

Thus, if denial of patent protection in a market also denies to consumers in that market access to the invented goods, then extending patent protection to the market is unambiguously welfare improving for everyone. Suppose, however, that this is not the case. Suppose instead that producers in the protected market do not manage to keep their technology secret and that a competitive supply of the invented 
products arises instead in the unprotected market. However realistic this possibility may be - and I do regard it to be the more likely case - it is surely the case that motivates most of the firms that have been lobbying for extending intellectual property protection under the GATT.

In this case of free foreign access to technology, it is still true that extension of patent protection creates a benefit. If competitive supplies are eliminated in the newly protected foreign market, then the inventing firms will earn additional monopoly profits and hence additional return on their inventions. Since, as argued above, the level of invention was already suboptimal, it follows that the resulting expansion of invention will increase world welfare. This is the benefit from extending patent protection to an additional market: the increased profit and consumer surplus (all positive) in both markets on the goods that are invented only as a result of extending protection.

There is, however, now also a cost. All of those goods which were available on the unprotected market previously will now be subject to monopoly pricing, and this will cause their consumption to be reduced to a suboptimal level. ${ }^{8}$ As is usual in the case of monopoly pricing, the loss to these (foreign) consumers exceeds the gain in monopoly profits to the supplier, and the difference is therefore a deadweight loss for the world as a whole.

Finally, as must already be obvious, there is an additional effect of extending patent protection which is neither a benefit nor a cost from the world's perspective, but which is undoubtedly more important than either in terms of understanding the position that countries take on this issue. That effect is the transfer of welfare from foreign consumers to domestic monopoly-inventors, and it is equal to the monopoly profits earned in the presence of patent protection on foreign sales. Even if neither foreign consumption nor the level of invention were to change in response to incentives, so that the benefits and costs enumerated above would be zero, this transfer of welfare could be considerable. It should be considered when one examines the implications of the policy for income distribution and equity.

\section{HOW FAR SHOULD PATENT PROTECTION BE EXTENDED?}

Given that there are these costs and benefits to extending patent protection to additional markets, plus a transfer effect, how far, geographically, should a system of patent protection extend? The answer might still be that it should cover all markets in the world, if there were practical obstacles to providing it only over a limited area. ${ }^{9}$ However, as the demands of the Uruguay Round make clear, we

\footnotetext{
${ }^{x}$ I am considering only the costs that arise when markets function costlessly and efficiently. In addition there are likely to be various costs of adjustment, as suppliers in the previously unprotected market must shut down and their workers find other employment.

"For instance, while it might seem reasonable to exempt only the poorest individuals within a given society from paying the monopoly prices permitted by patents, the difficulties of implementing such a system would surely be prohibitive.
} 
already have a system in which patent protection is granted in only some countries of the world, and while that may not be fair or optimal, it certainly does seem to be workable.

Let us consider first, then, just the costs and benefits of extending patent protection which were identified above, and ask what these imply, for the world as a whole, about the optimal geographical scope for patent protection. It is easy to see, as I will argue in a moment, that as protection is extended to a larger and larger portion of the world, the marginal benefits of extending it further decline and the marginal costs increase. Therefore, if the two are equal for some particular extent of patent protection, then this will be an optimal situation.

To see that the marginal benefits and costs behave in this way, consider the effect of extending protection to an additional market of some given size. The benefits from doing so arise entirely from the new inventions that this additional market will make profitable but which would not have been profitable to invent with the previous protected market size. The larger the previously protected market, however, the greater will be the number of inventions already invented, and the less desirable will be the ones that remain. Hence the marginal benefit declines.

Similarly, the cost of extending patent protection to this additional market is some fraction of the consumer surplus generated in this market by the inventions that would be undertaken anyway. This fraction is the amount by which consumer surplus declines on these goods when consumers are charged a monopoly price, minus the monopoly profits that are earned on the goods. ${ }^{10}$ This is therefore a deadweight loss to the world as a whole. The size of this fraction depends on the elasticity of demand for invented goods, and hence on the size of the monopoly markup, but there is no reason to expect this fraction to decline systematically as protection is extended. Therefore, as protection is extended further, and as more and more inventions are therefore stimulated and become subject to this markup, the deadweight loss due to extending to the additional market will grow.

All of this suggests, therefore, that there will be an optimal geographical extent of patent protection that need not be the whole world. I have not yet made the case, however, for it being less than the whole world.

In fact, such a result is not absolutely necessary, as can be seen from a simple extreme example. Suppose that the constellation of available inventions were such that there existed no inventions at all that would be profitable to invent for anything less than the entire world market. But suppose also that there was at least one invention which would be profitable to invent for the entire world market. That is, it would become profitable only if the very last consumer in the world were

\footnotetext{
"1 With linear demand, this fraction is one quarter. That is, with a switch from competitive to monopoly pricing in a market with a linear demand curve, three quarters of the previous consumer surplus is lost to consumers, but two thirds of that loss accrues to the monopolist in the form of profits, leaving a deadweight loss of one quarter of the competitive consumer surplus. See Deardorff (1990).
} 
included in the market where a monopoly price could be charged. In that very special case, there would be no cost to extending protection to cover this last consumer, and there would be the considerable benefit due to the new invention. Thus in this extreme case, the optimal geographical scope of patent protection would indeed be the whole world.

The example is so extreme, however, that it easily suggests why this is not normally the case. Suppose, as we contemplate extending protection to the last consumer, or even to the last country, that there does exist a plentiful array of inventions that could be supported by the rest of the world market excluding this consumer or country. Then these existing inventions, as just discussed, determine the deadweight loss due to extending protection, and at the same time, since these will always be the most profitable of potential inventions, they suggest the undesirability of the inventions that remain. That is, as long as the number of inventions that can be supported without extending patent protection is at all large, one can presume that the benefits of extending protection still further, and hence stimulating a few not-very-desirable inventions, will be outweighed by the costs. Thus I believe that there is a strong presumption in favour of the optimal geograhic scope for patent protection being something less than the entire world. ${ }^{1}$

\section{WHO SHOULD BE EXEMPT FROM PATENT PROTECTION?}

While I have argued that some portion of the world should be exempt from a system of patent protection, in order to maximise the welfare of the world as a whole, I have not yet discussed what portion of the world this should be. While it is perhaps not possible to make a formal argument in this regard, there are a number of reasons why I think it makes sense to exempt developing countries, starting with the poorest of them.

The most compelling reason for this is an equity argument, based upon the effect on the world distribution of income. Patent protection has the effect of transferring income from consumers in the protected market to the monopoly inventor/producers. Since technological innovation is itself a part of the development process and seems to occur more rapidly the more developed a country is, these monopolists reside predominantly in the richest countries of the world. Therefore, extending patent protection to poor countries involves a transfer of welfare from the poor to the rich. Assuming that greater world-wide income equality is a desirable goal, for any number of reasons, this surely suggest that it should be the poorest of countries that are exempted.

13 In Deardorff (1990) I derive this result formally from a simple model. By assuming that both demand functions and a function describing the potential inventions are continuous and linear, the conditions under which global patent protection is suboptimal are made quite weak. 
A second reason is that a system of patent protection may be more likely to induce a substantial flow of inventions in developed countries. Residents of developed countries have more resources to devote to inventive activities, and perhaps a greater inclination to do so. Therefore, if we want patent protection to cover at least those parts of the world where invention takes place, this too suggests that it be only the developing world that is excluded. ${ }^{12}$

Finally, there is a political reason for letting it be only the poorest of countries that are exempted from patent protection. As the pressures to include intellectual property issues in the Uruguay Round make clear, the owners of patents and potential patents make up a large and powerful constituency in favour of extending the system. This constituency works most effectively at home, and therefore has led the developed world to the system of intellectual property protection which we have today. The poorest countries of the developing world, on the other hand, often have no such strong constituency, and they may not acquire one as long as they remain poor. Therefore, to exempt developed countries from patent protection would be to run counter to their internal domestic political forces, while to exempt many developing countries most likely would not. Since in this case the political and economic forces seem to be pushing in the same direction, I see no reason to resist them.

A harder question is where to draw the line between the poorest countries that should be exempt from patent protection and the richest countries that should not. Should the newly industrialising countries (NICs), for example, be exempl? It is clear that as countries do succeed in developing, they eventually begin innovating extensively, and they come to see the benefits for themselves of a system of patent protection. On the other hand, to wait until they voluntarily adopt such a system is to wait too long, at least from the standpoint of world efficiency, since patent protection will always yield some benefit external to their own societies. Thus I can see the need for the developed countries of the world to lean on the most successful NICs to get them to adopt intellectual property protection somewhat earlier than they would voluntarily.

\section{CONCLUSION}

This discussion has focused on a narrow aspect of the intellectual property rights debate. I have looked only at patent protection, and my analysis has been based primarily on a simple static model of how patent rights affect innovation and market structure. Some will no doubt argue that I have missed the point, in a variety

\footnotetext{
1: On the other hand. there really is no need for inventors to reside in an area where there is patent protection, as long as they are eligible to be granted patents elsewhere. Thus the argument that developing countries need patent protection in order to encourage their own residents to innovate is not compelling.
} 
of ways, and that a different analysis would yield a different result. That may be true. Perhaps there are, for example, dynamic considerations that could make a compelling case for extending patent protection even into the poorest and most remote of countries in the world. If I could be convinced that a patent system would be the magical key to unlocking the secret of development for those who need it most, then I would gladly change the conclusion of this paper. But at the moment I do not see how that case can credibly be made.

Instead, the point I have tried to make here is that resistance to adopting patent protection in developing countries is not by any means the wrong-headed folly that advocates of extending protection in the developed countries would like us to believe. Failure to erect and enforce a patent system is not analogous to, say, the failure of similar countries to open their markets to trade. More liberal trade policies will enhance the welfare of developing countries, as they do the welfare of the world, and the only costs are distributional consequences within the countries that probably need to be dealt with in any case. But patent protection is almost certain to redistribute welfare away from developing countries. And it may even lower world welfare, as I have argued here, if it is extended too far to cover all the countries of the world. If nothing else, the developing countries that resist this change should be given a fair hearing.

\section{REFERENCES}

Chin, J.C. and G.M. Grossman (1990), 'Intellectual Property Rights and North-South Trade', in R. W. Jones and A. O. Krueger (eds.), The Political Economy of International Trade: Essays in Honor of Robert E. Baldwin, Cambridge, MA: Basil Blackwell.

Deardorff, A.V. (1990), 'Welfare Effects of Global Patent Protection', in process.

Deardorff, A.V. and R.M. Stern (1983), 'Economic Effects of the Tokyo Round', Southern Economic' Jounal 49, 605-24.

Deardorff, A.V. and R.M. Stern (1986), The Michigan Model of World Production and Trade, Cambridge, MA: MIT Press. 
